ARTICLE

https://doi.org/10.1038/s41467-019-13024-5

\title{
Practical and stereoselective electrocatalytic 1,2-diamination of alkenes
}

\author{
Chen-Yan Cai ${ }^{1}$ Xiao-Min Shu ${ }^{1} \&$ Hai-Chao Xu (iD) ${ }^{1 \star}$
}

The 1,2-diamine motif is widely present in natural products, pharmaceutical compounds, and catalysts used in asymmetric synthesis. The simultaneous introduction of two amino groups across an alkene feedstock is an appealing yet challenging approach for the synthesis of 1,2diamines, primarily due to the inhibitory effect of the diamine products to transition metal catalysts and the difficulty in controlling reaction diastereoselectivity and regioselectivity. Herein we report a scalable electrocatalytic 1,2-diamination reaction that can be used to convert stable, easily available aryl alkenes and sulfamides to 1,2-diamines with excellent diastereoselectivity. Monosubstituted sulfamides react in a regioselective manner to afford 1,2-diamines bearing different substituents on the two amino groups. The combination of an organic redox catalyst and electricity not only obviates the use of any transition metal catalyst and oxidizing reagent, but also ensures broad reaction compatibility with a variety of electronically and sterically diverse substrates. 
1,2-Diamine is a prevalent structural motif in natural products, pharmaceutical compounds, and molecular catalysts ${ }^{1}$. Alkene $1,2-$ diamination and 1,2-diazidation reactions are among the most straightforward and attractive strategies for 1,2-diamine synthesis, especially considering the easy accessibility and handling of alkene substrates ${ }^{2}$. Significant progress has been achieved over the past decades in alkene 1,2-diamination and 1,2-diazidation reactions, mainly through transition metal catalysis (Fig. 1a, b $)^{3-18}$. Unfortunately, these methods are not without drawbacks. First, the use of stoichiometric amounts of transition metal reagents (e.g., osmium or cobalt) ${ }^{3,7}$, chemical oxidants (e.g., iodine (III) reagents or organic peroxides $)^{5,6,10,11}$, or azide reagents ${ }^{8-14}$ raises cost, environmental, and safety issues, especially for large-scale applications ${ }^{19,20}$. Second, they are often limited in substrate scope, sometimes requiring special amination reagents (e.g., diaziridinone and its analogs $4,15,16$, or azido-iodine compounds $\left.{ }^{9}\right)$. Other challenges that need to be addressed include unsatisfactory diastereoselectivity for internal alkenes and

a Previous work: alkene 1,2-diamination via activation of nitrogenous reagents (refs. 3-6)
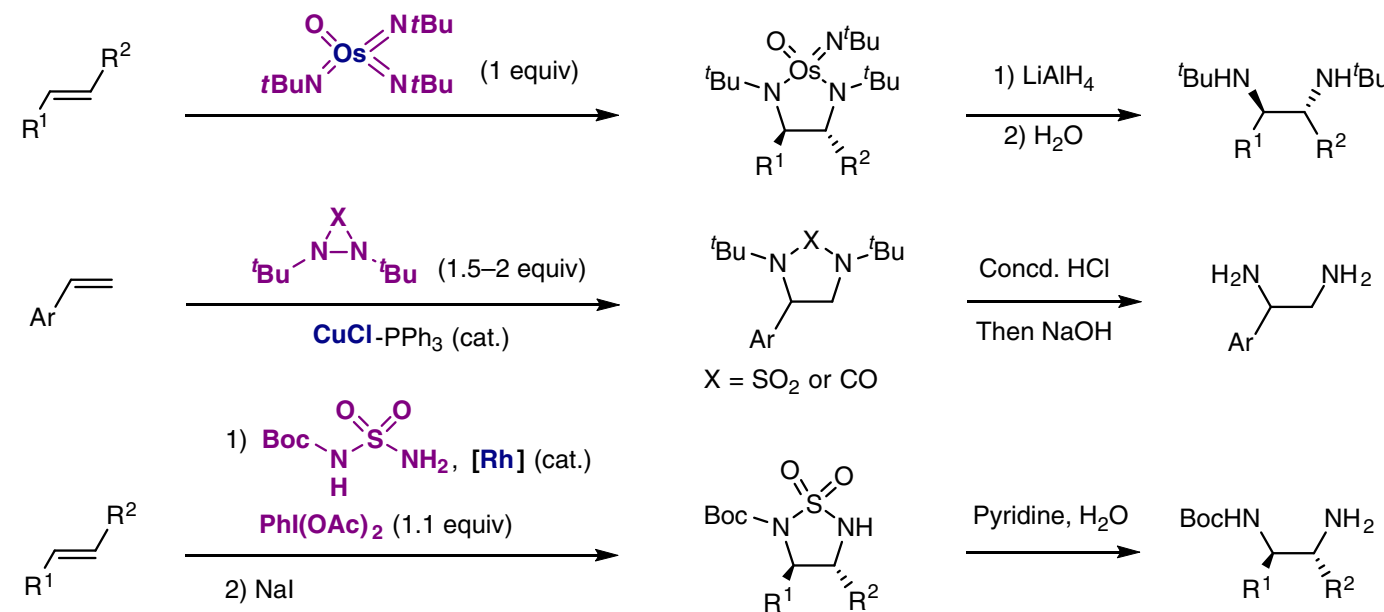<smiles>[R7]C1NS(=O)(=O)N(C(=O)OCc2ccccc2)C1[R7]</smiles>
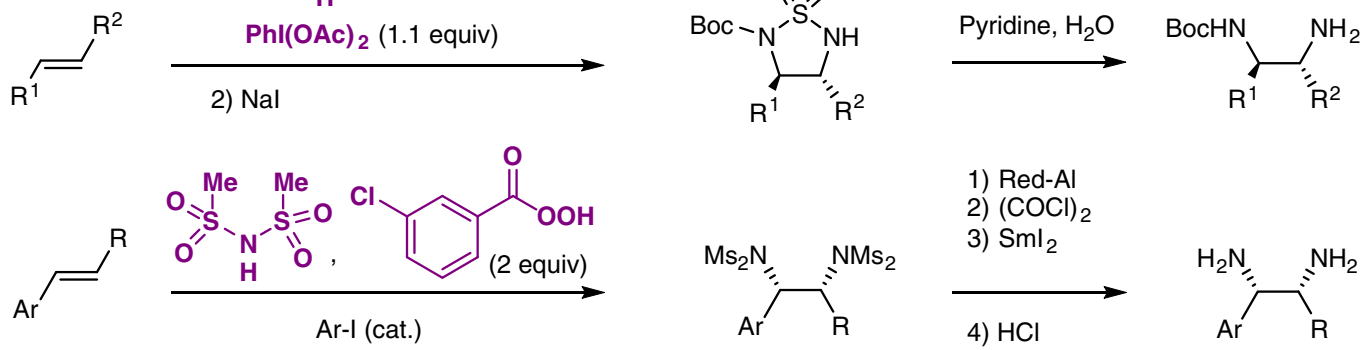

b Previous work: catalytic alkene 1,2-diazidation via activation of azido donor

[Fe] or $[\mathrm{Cu}]$ (cat.) + azido source/oxidant (refs. 9-11)

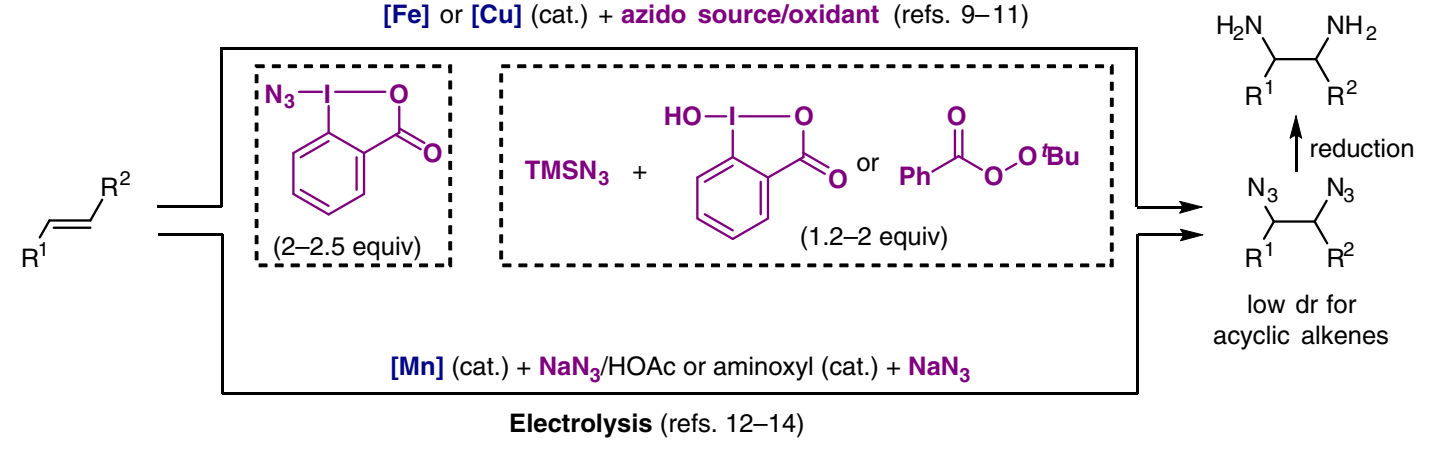

c This work: diastereoselective 1,2-diamination of alkenes via activation of alkenes
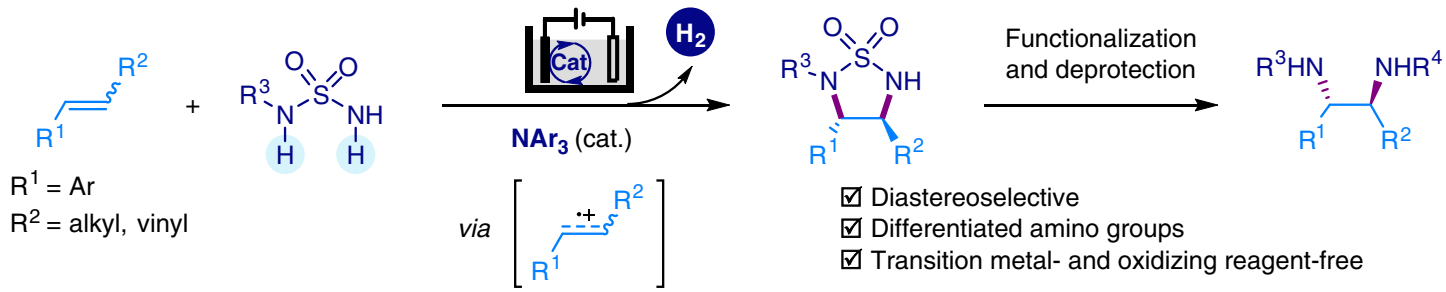

$\square$ Diastereoselective

$\square$ Differentiated amino groups

$\square$ Transition metal- and oxidizing reagent-free

Fig. 1 Synthesis of 1,2-diamines. a, b Representative examples of established 1,2-diamine synthesis via vicinal difunctionalization of alkenes. c Proposed electrochemical 1,2-diamination of alkenes with sulfamides via dehydrogenative annulation and removal of the sulfonyl group. Boc, tert-butyloxycarbonyl; Ms, methanesulfonyl; TMS, trimethylsilyl 
poor differentiation of the two amino groups in the diamine products.

Organic electrochemistry, which drives redox processes with electric current, is increasingly considered as a highly sustainable and efficient synthetic method ${ }^{21-34}$. One key advantage of using electrochemical methods is that the reaction efficiency and selectivity can often be boosted by manipulating the electric current or potential, allowing one to achieve transformations that are otherwise synthetically inaccessible. In this context, Yoshida ${ }^{35}$ reported isolated examples of alkene diamination through intramolecular trapping of alkene radical cations. Shäfer ${ }^{36}$ reported an early example of electrochemical 1,2-diazidation of simple alkenes with $\mathrm{NaN}_{3}$ in acetic acid. Lin and co-workers recently developed a $\mathrm{NaN}_{3}$-based electrocatalytic olefin 1,2-diazidiation reaction that showed an exceptional substrate scope and broad functional group compatibility (Fig. 1b, bottom) $)^{12-14}$.

Building on our experience with electrochemical alkene difunctionalization ${ }^{37,38}$, herein we report a diastereoselective electrocatalytic 1,2-diamination reaction of di- and tri-substituted alkenes using easily available and stable sulfamides as amino donors. A wide variety of 1,2-diamines, where the two amino groups are functionalized with different substituents, can be prepared via regio- and diastereoselective diamination using monosubstituted sulfamides. The electrosynthetic method employs an organic redox catalyst and proceeds through $\mathrm{H}_{2}$ evolution, while obviating the need for transition metal catalysts and external chemical oxidants.

\section{Results}

Design plan. Inspired by our previously work on electrochemical alkene dioxygenation reactions ${ }^{38}$, we envisioned the trapping of an electrocatalytically generated alkene radical cation $\mathbf{I I}^{\bullet+}$ with a sulfamide III to generate a carbon radical IV (Fig. 2a). ${ }^{39-43}$ Single-electron transfer oxidation of IV by $\mathbf{I}^{\bullet+}$ would produce a carbocation $\mathbf{V}$, which could then undergo cyclization to afford the cyclic sulfamide VI. Cyclization of $\mathbf{V}$ has a key role in governing the stereoselectivity of the 1,2-diamination, in which the alkeneoriginated substituents $\mathrm{R}^{1}$ and $\mathrm{R}^{2}$ are positioned on opposite sides of the nascent five-membered ring to minimize steric repulsion.
The electrons that the alkene loses to the anode would eventually combine with the protons at the cathode to form $\mathrm{H}_{2}$, thereby obviating the need for external electron and proton acceptors. The controlled formation of alkene radical cations at low concentrations is essential to overcome their strong propensity toward self-dimerization or reaction with the alkene precursors, especially on electrode surface ${ }^{44-46}$. This could be accomplished by conducting electrolysis indirectly in the presence of a redox catalyst rather than direct electrolysis. Measuring catalytic current through cyclic voltammetry 33,47 , with tris(2,4-dibromophenyl) amine $\left(1, E_{\mathrm{p} / 2}=1.48 \mathrm{~V}\right.$ vs saturated calomel electrode (SCE)) as the redox catalyst, confirmed the facile electrocatalytic oxidation of the alkenes $2\left(E_{\mathrm{p} / 2}=1.66 \mathrm{~V}\right.$ vs SCE $)$ and $3\left(E_{\mathrm{p} / 2}=1.80 \mathrm{~V}\right.$ vs $\mathrm{SCE}$ ) that bears an electron-withdrawing ester group (Fig. $2 \mathrm{~b}, \mathrm{c}$ ).

Reaction optimization. The 1,2-diamination of aryl alkene 2 with sulfamide $\mathbf{4}$ was chosen as a model reaction for optimizing the electrochemical conditions. The electrolysis was conducted at RT and at a constant current in a three-necked round-bottomed flask equipped with a reticulated vitreous carbon (RVC) anode and a platinum plate cathode. The optimal reaction system consisted of triarylamine $\mathbf{1}(10 \mathrm{~mol} \%)$ as redox catalyst, ${ }^{i} \mathrm{PrCO}_{2} \mathrm{H}$ (2 equiv) and $\mathrm{BF}_{3} \cdot \mathrm{Et}_{2} \mathrm{O}$ (0.5 equiv) as additives, $\mathrm{Et}_{4} \mathrm{NPF}_{6}$ as supporting electrolyte to increase conductivity, and $\mathrm{MeCN} /$ $\mathrm{CH}_{2} \mathrm{Cl}_{2}$ (1:2) as solvent. Under these conditions, the diamination product 5 was obtained in $72 \%$ yield with excellent diastereoselectivty ( $>20: 1 \mathrm{dr}$ ) even though a starting mixture of $Z / E$ isomers of 2 was used (in a ratio of 5.6:1) (Table 1, entry 1). Independent reaction using a pure $E$ - or $Z$-isomer of 2 afforded the same trans diastereomer 5 in $65 \%$ and $69 \%$ yield, respectively. Similar results could also be obtained when the reaction was performed in ElectraSyn 2.0, a commercial apparatus (Table 1, entry 2). The use of $\mathrm{MeCN}$ as solvent instead of $\mathrm{MeCN} / \mathrm{CH}_{2} \mathrm{Cl}_{2}$ resulted in a lower yield of $50 \%$ (Table 1 , entry 3 ). Other triarylamine derivatives such as $6\left(E_{\mathrm{p} / 2}=1.06 \mathrm{~V}\right.$ vs SCE $), 7\left(E_{\mathrm{p} / 2}=\right.$ $1.26 \mathrm{~V}$ vs $\mathrm{SCE})$, and $8\left(E_{\mathrm{p} / 2}=1.33 \mathrm{~V}\right.$ vs $\left.\mathrm{SCE}\right)$ were found to be less effective in promoting the formation of $\mathbf{5}$ probably because of their lower oxidation potentials (Table 1, entries 4-6). Control experiments showed that the triarylamine catalyst (Table 1, entry a

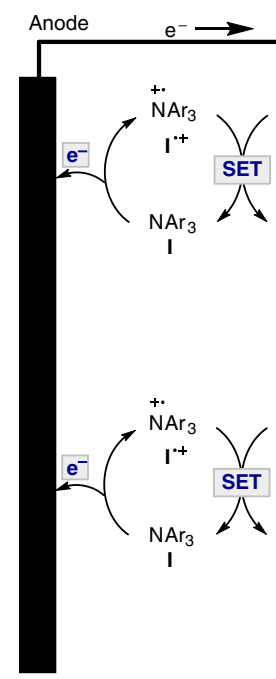

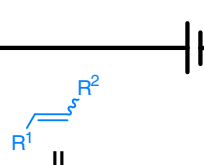

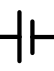

$\mathrm{R}^{1}$ II

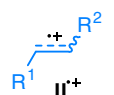

IV
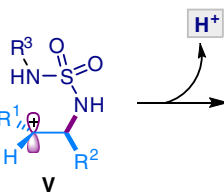

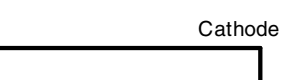

b
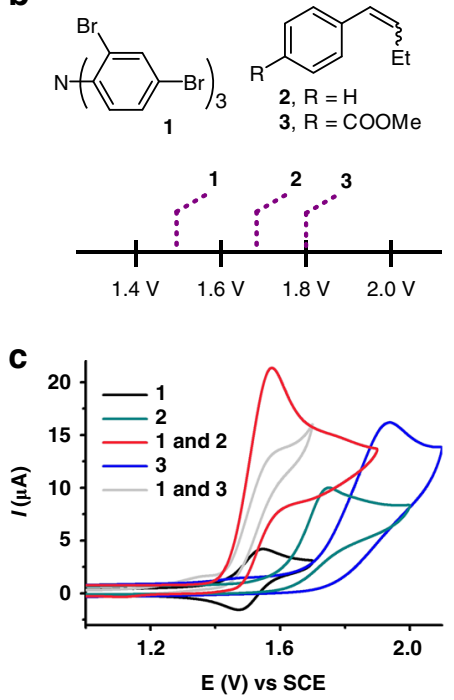

Fig. 2 Proposed reaction design. a The proposed reaction mechanism. The process combines anodic oxidation and cathodic proton reduction to achieve the alkene 1,2-diamination via $\mathrm{H}_{2}$ evolution. The electrocatalytic activation of the alkene through single-electron transfer (SET) oxidation generates the alkene

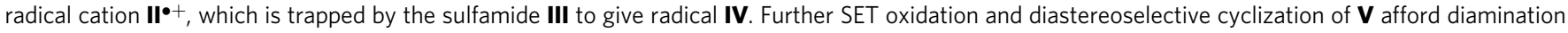

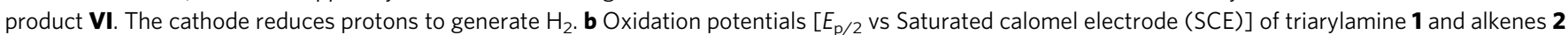
and 3. c Cyclic voltammetry. The studies show that triarylamine $\mathbf{1}$ can catalyze the oxidation of aryl alkenes $\mathbf{2}$ and $\mathbf{3}$ 


\section{Table 1 Optimization of reaction conditions ${ }^{\mathrm{a}}$}

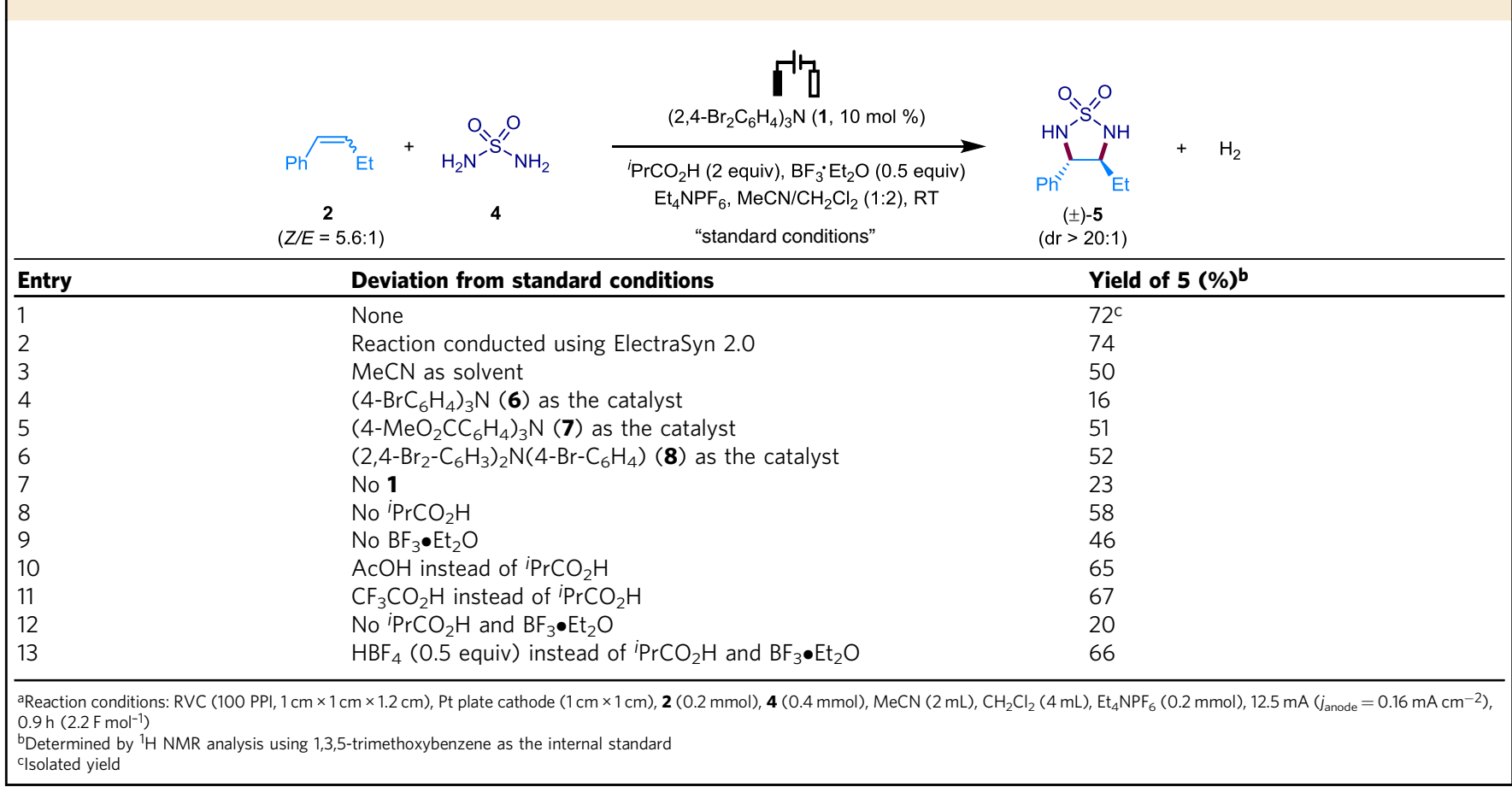

7), ${ }^{i} \mathrm{PrCO}_{2} \mathrm{H}$ (Table 1, entry 8) and $\mathrm{BF}_{3} \cdot \mathrm{Et}_{2} \mathrm{O}$ (Table 1, entry 9) were all indispensable for achieving optimal reaction efficiency. Replacing ${ }^{i} \mathrm{PrCO}_{2} \mathrm{H}$ with $\mathrm{AcOH}$ (Table 1, entry 10 ) or $\mathrm{CF}_{3} \mathrm{CO}_{2} \mathrm{H}$ (Table 1, entry 11) led to a slight yield reduction. The yield of 5 dropped to $20 \%$ in the absence of ${ }^{i} \mathrm{PrCO}_{2} \mathrm{H}$ and $\mathrm{BF}_{3} \cdot \mathrm{Et}_{2} \mathrm{O}$ (Table 1, entry 12). On the other hand, substituting $\mathrm{HBF}_{4}$ (0.5 equiv) for both ${ }^{i} \mathrm{PrCO}_{2} \mathrm{H}$ and $\mathrm{BF}_{3} \cdot \mathrm{Et}_{2} \mathrm{O}$ rescued the formation of 5 to a significant extent (Table 1, entry 13). We speculated that ${ }^{i} \mathrm{PrCO}_{2} \mathrm{H}$ and $\mathrm{BF}_{3} \cdot \mathrm{Et}_{2} \mathrm{O}$ could complex to form a stronger protic acid, which is helpful for cathodic proton reduction and thus avoiding unwanted reduction of the substrates or products ${ }^{48}$.

Evaluation of substrate scope. We next explored the scope of alkenes by using sulfamide $\mathbf{4}$ as the coupling partner (Table 2). The aryl ring in the 1,2-disubstituted alkene could be functionalized with an electronically diverse set of substituents, including $\mathrm{Me}(\mathbf{9}),{ }^{t} \mathrm{Bu}(\mathbf{1 0})$, halogens (F, Cl, Br, I; 11-16), and ester (17 and 18), at various positions of the phenyl ring. Alkenes carrying a 2,5-disubstituted phenyl ring were also found to be suitable substrates (19 and 20). The $\beta$-position of the styrenyl alkene showed broad tolerance for alkyl substituents of different sizes, such as $\mathrm{Me}$ (21), cyclohexyl (Cy; 22), and ${ }^{t^{\mathrm{Bu}}}$ (23). Terminal alkenes were less-efficient substrates probably owing to the facile dimerization/oligomerization of these alkenes ${ }^{44,49}$. As an example, the reaction of 1,1-diphenylethylene with 4 afforded the desired product $\mathbf{2 4}$ in $40 \%$ yield. One the other hand, trisubstituted cyclic (25) and acyclic (26 and 27) alkenes reacted smoothly to afford the corresponding cyclic sulfamides in good to excellent diastereoselectivity. Meanwhile, 1,2-diamination of 1,3dienes showed satisfactory regioselectivity in favor of the alkenyl moiety distal to the phenyl group (28 and 29). Note that triarylamine $\mathbf{6}$ was employed as redox catalyst to overcome the relatively low oxidation potentials of 1,3 -dienes $\left(E_{\mathrm{p} / 2}=1.29 \mathrm{~V}\right.$ vs SCE) and avoid oxidizing the remaining alkene moiety in the products. Furthermore, the electrochemical alkene 1,2-diamination reaction was compatible with alkylbromide (30 and $\mathbf{3 1}$ ), alkylchloride (32), ester (17, 18, 33), sulfonic ester (34), sulfonamide (35), amide (36), heterocycles such as furan (37) and thiophene (38), cyclic ether (39), and even oxidation-labile secondary and tertiary amines (40-42). Alkenes derived from estrone (43), fasudil (44), and quinine (45) reacted with similar success. The electron-rich amino groups in the cases of 40-42, 44, and 45 were masked as ammonium salts by the addition of $\mathrm{HBF}_{4}$ to prevent oxidative decomposition.

The electrochemical method also proved capable of generating 1,2-diamine products that carry two differently decorated amino groups, or cyclic 1,2-diamines (Table 2). For example, we succeeded in the 1,2-diamination with a wide array of asymmetric sulfamides bearing a single alkyl group on one of its nitrogen atoms. In these cases, the alkyl substituent could be primary (46, $47)$, secondary $(48)$, tertiary $(49,50)$, or functionalized with ester (51), $\mathrm{CF}_{3}$ (52), alkylchloride (53), carboxylic acid (54), free alcohol (55), alkene (56), or alkyne (57). These asymmetric sulfamides reacted in a strictly regioselective manner. Notably, bridged bicyclic products (58-60) could be obtained by 1,2diamination of cyclic sulfamide substrates. The structure of 59 was further confirmed by single crystal X-ray analysis.

Gram scale synthesis and product transformations. To further demonstrate the synthetic utility of our electrochemical method, we reacted alkene 61 or 62 with sulfamide 4,63 , or 64 on gram or even decagram scale and obtained the corresponding products $(21,22,48$, and 59) in good yields (Fig. 3). Deprotection of theses cyclic sulfamides with $\mathrm{HBr}$ or hydrazine furnished diamines 6567, 69, and 70. Protection of the free amino group in 67 with $\mathrm{Boc}_{2} \mathrm{O}$ resulted in the formation of $\mathbf{6 8}$, whose two amino groups carries different substituents and therefore is amenable to further chemoselective derivatization. On the other hand, 48 could be converted to diamine $\mathbf{6 9}$, also with differently decorated amino groups, through methylation and subsequent sulfonyl removal.

\section{Methods}

Representative procedure for the synthesis of $\mathbf{5}$. To a $10-\mathrm{mL}$ three-necked round-bottomed flask were added sulfamide 4 ( $0.4 \mathrm{mmol}, 2$ equiv), triarylamine 1 (0.02 mmol, 0.1 equiv) and $\mathrm{Et}_{4} \mathrm{NPF}_{6}(0.2 \mathrm{mmol}, 1$ equiv). The flask was equipped 


\section{Table 2 Substrate scope ${ }^{a}$}

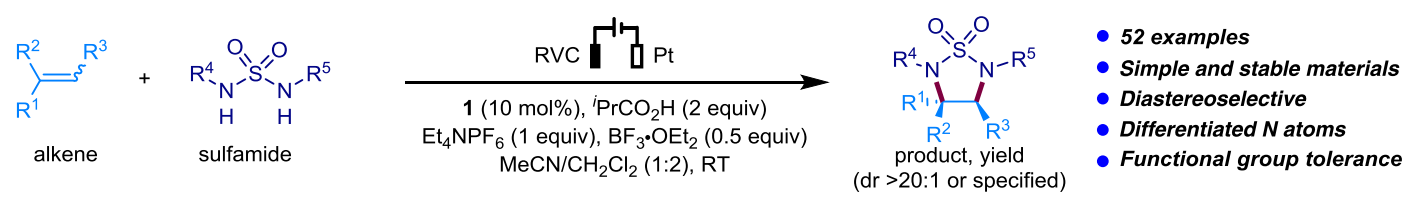

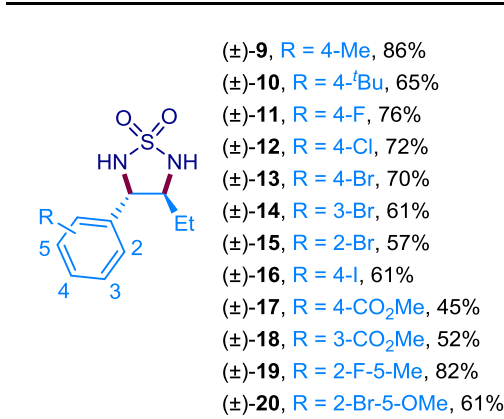

\section{Variation of alkene}
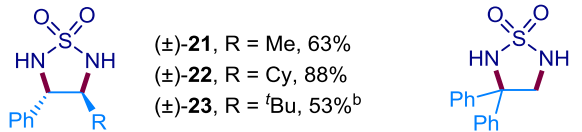

(土)-24, $40 \%$

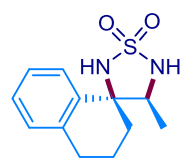

$( \pm)-26,37 \%^{c}$

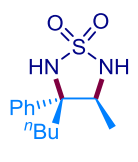

$( \pm)-27,79 \%(9: 1 \mathrm{dr})$<smiles>CCC1NS(=O)(=O)N[C@@H]1/C=C/c1ccccc1</smiles>

$( \pm)-28,67 \%$ d

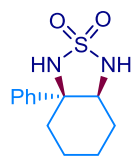

(土)-25, $77 \%$<smiles>CC1(C)NS(=O)(=O)N[C@H]1/C=C/c1ccccc1</smiles>

( \pm$)-29,47 \%{ }^{d}$

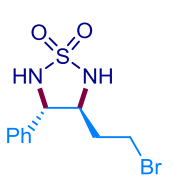

(士)-30, 61\%

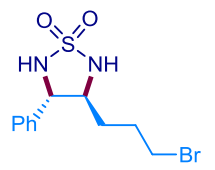

(士)-31, 55\%<smiles>CC1NS(=O)(=O)N[C@]1(C)CCCCl</smiles>

( \pm )-32, 74\% (8:1 d.r.)<smiles>CCCCOCC[C@H]1NS(=O)(=O)NC1(c1ccccc1)c1ccccc1</smiles>

(土)-33, 61\%<smiles>O=S1(=O)NC(CCO[Ga])C(c2ccccc2)N1</smiles>

(士)-34, $80 \%$<smiles>O=S1(=O)NC(C[NH2+][Na])[C@@]([PH2+])(c2ccccc2)N1</smiles>

(士)-35, 66\%<smiles>CCCCCNC(=O)c1cc(OC)cc([C@]23CCCCC2NS(=O)(=O)N3)c1</smiles>

(士)-36, $45 \%$

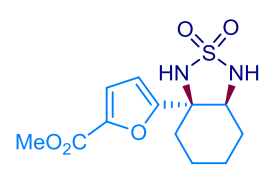

$( \pm)-37,90 \%$

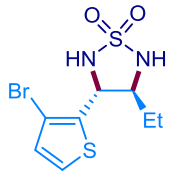

(士)-38, 69\%

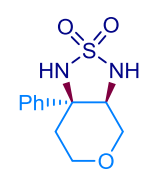

(土)-39, 57\%

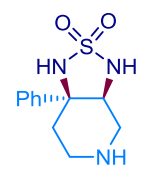<smiles>O=S1(=O)NC(CCN2CCOCC2)C(c2ccccc2)(c2ccccc2)N1</smiles>

$( \pm)-40,59 \%^{e}$

( \pm - $41,95 \%^{\mathrm{e}}$

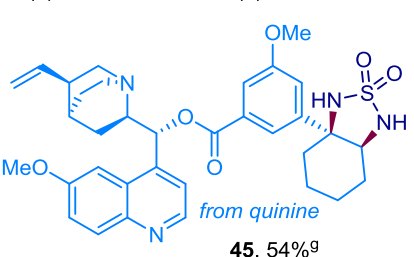

$( \pm)-42,72 \%$

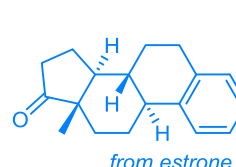

43, $76 \%$

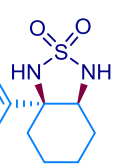

(1:1 dr relative to estrone)

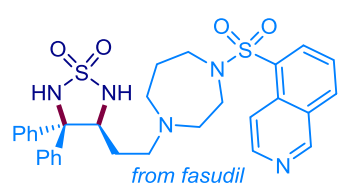

$( \pm)-44,82 \%{ }^{g}$

(1:0.8 dr relative to quinine)

Variation of sulfamide ${ }^{b}$

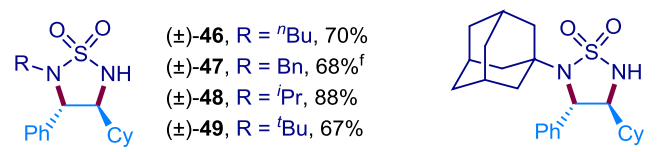

(士)-50, 91\%<smiles>[R]CN1C([PbH])[C@H]([AlH2])NS1(=O)=O</smiles>

(士)-51, R $=\mathrm{CO}_{2} \mathrm{Et}, 83 \%$

(士)-52, R $=\mathrm{CF}_{3}, 70 \%$

$( \pm)-53, \mathrm{R}=\mathrm{CH}_{2} \mathrm{Cl}, 70 \%$<smiles>[CH]C1NS(=O)(=O)N(CC=C)[C@@H]1c1ccccc1</smiles>

$( \pm)-56,79 \%$<smiles>C#CCN1[C@H](c2ccccc2)C([AlH2])NS1(=O)=O</smiles>

$( \pm)-57,79 \%$

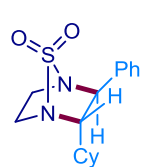

$( \pm)-58,44 \%$

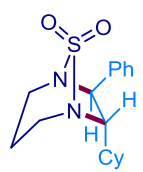

( \pm -59, $77 \%$<smiles>O=C(O)CN1[C@H](c2ccccc2)[C@@H](Cl)NS1(=O)=O</smiles>

( \pm )-54, $47 \%$

$$
\text { - }
$$

(士)-55, 54\%

aReaction conditions: alkene $(0.2 \mathrm{mmol})$, sulfamide $(0.4 \mathrm{mmol}), 0.9-3.7 \mathrm{~h}\left(2.0-8.7 \mathrm{~F} \mathrm{~mol}^{-1}\right)$. All yields are isolated yields

beaction with sulfamide $(1.2 \mathrm{mmol})$ and $\mathrm{BF}_{3} \bullet \mathrm{OEt}_{2}(0.2 \mathrm{mmol})$

cReaction without $\mathrm{BF}_{3} \bullet \mathrm{OEt}_{2}$

dReaction with $6(10 \mathrm{~mol} \%)$ as the catalyst

eReaction with $\mathrm{HBF}_{4}(0.3 \mathrm{mmol})$ instead of $\mathrm{BF}_{3} \bullet \mathrm{OEt}_{2}$

fReaction with sulfamide $(0.8 \mathrm{mmol})$ and $\mathrm{BF}_{3} \bullet \mathrm{OEt}_{2}(0.2 \mathrm{mmol})$

gReaction with $\mathrm{HBF}_{4}(0.4 \mathrm{mmol})$ instead of $\mathrm{BF}_{3} \bullet \mathrm{OEt}_{2}$. Cy, cyclohexyl; Ts, tosyl 


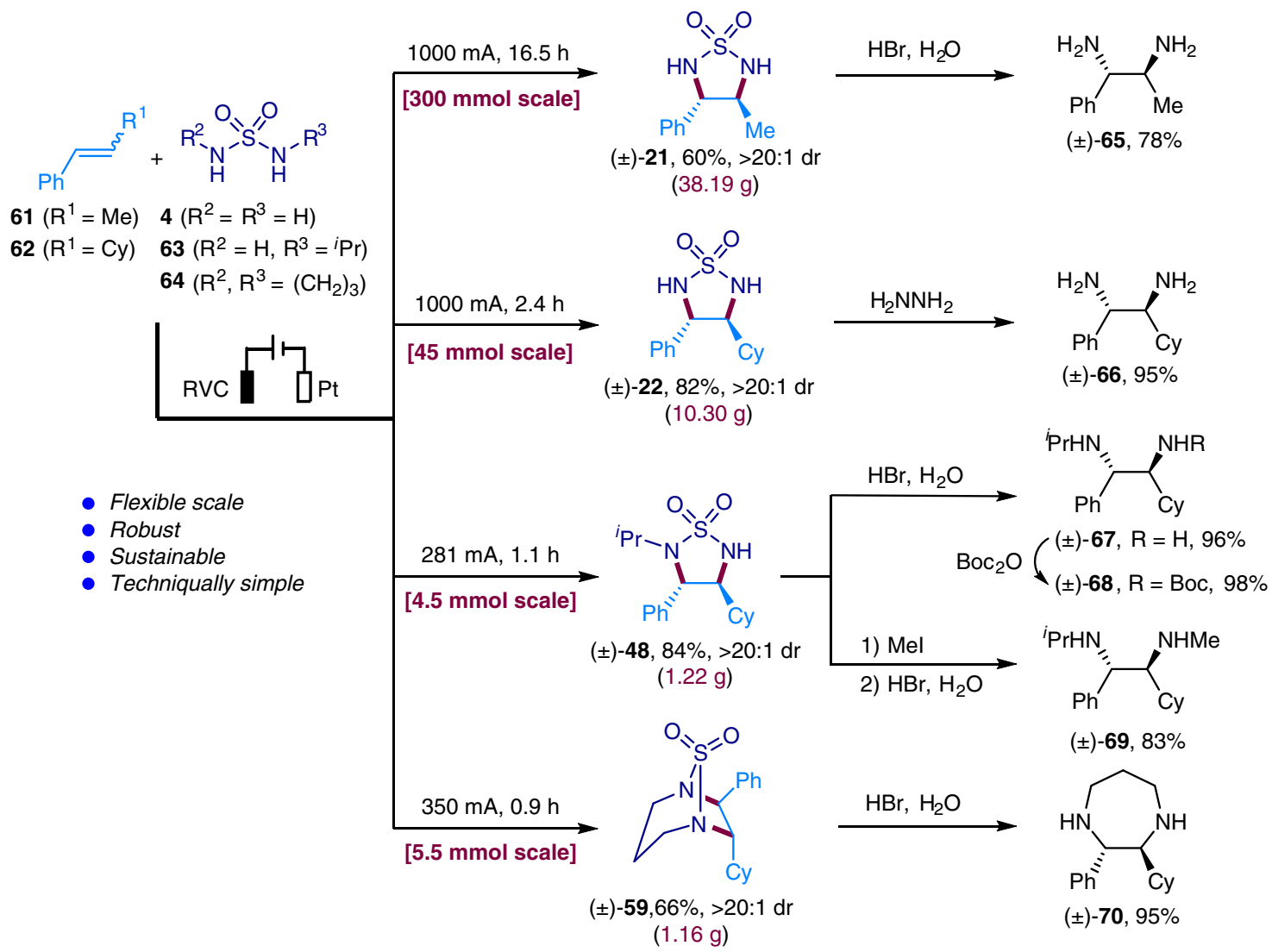

Fig. 3 Gram scale synthesis and further product transformations. Gram scale synthesis of compounds $\mathbf{2 1}, \mathbf{2 2}, \mathbf{4 8}$, and $\mathbf{5 9}$, and their conversion to amines

with an RVC anode (100 PPI, $1 \mathrm{~cm} \times 1 \mathrm{~cm} \times 1.2 \mathrm{~cm})$ and a platinum plate $(1 \mathrm{~cm} \times$ $1 \mathrm{~cm})$ cathode. After flushing the flask with argon, $\mathrm{MeCN}(2 \mathrm{~mL}), \mathrm{CH}_{2} \mathrm{Cl}_{2}(4 \mathrm{~mL})$, alkene 2 (0.2 mmol, 1 equiv), ${ }^{i} \mathrm{PrCO}_{2} \mathrm{H}\left(0.4 \mathrm{mmol}, 2\right.$ equiv) and $\mathrm{BF}_{3} \cdot \mathrm{Et}_{2} \mathrm{O}$ $(0.1 \mathrm{mmol}, 0.5$ equiv) were added sequentially. The constant current $(12.5 \mathrm{~mA})$ electrolysis was carried out at room temperature until complete consumption of 2 (monitored by TLC or ${ }^{1} \mathrm{H}$ NMR). Saturated $\mathrm{NaHCO}_{3}$ solution was added. The resulting mixture was extracted with EtOAc $(3 \times 20 \mathrm{~mL})$. The combined organic solution was dried over anhydrous $\mathrm{Na}_{2} \mathrm{SO}_{4}$ and concentrated under reduced pressure. The residue was separated by silica gel chromatography and the product 5 obtained in $72 \%$ yield by eluting with ethyl acetate/hexanes. All new compounds were fully characterized (See the Supplementary Methods).

\section{Data availability}

The X-ray crystallographic coordinates for structures reported in this article have been deposited at the Cambridge Crystallographic Data Centre (CCDC), under deposition number CCDC 1938821 (59). The data can be obtained free of charge from The Cambridge Crystallographic Data Centre [http://www.ccdc.cam.ac.uk/data_request/cif]. The data supporting the findings of this study are available within the article and its Supplementary information files. Any further relevant data are available from the authors on request.

Received: 16 August 2019; Accepted: 17 October 2019;

Published online: 31 October 2019

\section{References}

1. Lucet, D., Le Gall, T. \& Mioskowski, C. The chemistry of vicinal diamines. Angew. Chem. Int. Ed. 37, 2580-2627 (1998).

2. Cardona, F. \& Goti, A. Metal-catalysed 1,2-diamination reactions. Nat. Chem. 1, 269-275 (2009)

3. Chong, A. O., Oshima, K. \& Sharpless, K. B. Synthesis of dioxobis(tertalkylimido)osmium(VIII) and oxotris(tert-alkylimido)osmium(VIII) complexes. Stereospecific vicinal diamination of olefins. J. Am. Chem. Soc. 99, 3420-3426 (1977).

4. Zhu, Y., Cornwall, R. G., Du, H., Zhao, B. \& Shi, Y. Catalytic diamination of olefins via N-N bond activation. Acc. Chem. Res. 47, 3665-3678 (2014).
5. Olson, D. E., Su, J. Y., Roberts, D. A. \& Du Bois, J. Vicinal diamination of alkenes under Rh-catalysis. J. Am. Chem. Soc. 136, 13506-13509 (2014).

6. Muñiz, K., Barreiro, L., Romero, R. M. \& Martínez, C. Catalytic asymmetric diamination of styrenes. J. Am. Chem. Soc. 139, 4354-4357 (2017).

7. Becker, P. N., White, M. A. \& Bergman, R. G. A new method for 1,2diamination of alkenes using cyclopentadienylnitrosylcobalt dimer/NO/ $\mathrm{LiAlH}_{4}$. J. Am. Chem. Soc. 102, 5676-5677 (1980).

8. Zhang, B. \& Studer, A. Copper-catalyzed intermolecular aminoazidation of alkenes. Org. Lett. 16, 1790-1793 (2014).

9. Fumagalli, G., Rabet, P. T. G., Boyd, S. \& Greaney, M. F. Three-component azidation of styrene-type double bonds: light-switchable behavior of a copper photoredox catalyst. Angew. Chem. Int. Ed. 54, 11481-11484 (2015).

10. Yuan, Y.-A., Lu, D.-F., Chen, Y.-R. \& Xu, H. Iron-catalyzed direct diazidation for a broad range of olefins. Angew. Chem. Int. Ed. 55, 534-538 (2016).

11. Shen, S.-J., Zhu, C.-L., Lu, D.-F. \& Xu, H. Iron-catalyzed direct olefin diazidation via peroxyester activation promoted by nitrogen-based ligands. ACS Catal. 8, 4473-4482 (2018).

12. Fu, N., Sauer, G. S., Saha, A., Loo, A. \& Lin, S. Metal-catalyzed electrochemical diazidation of alkenes. Science 357, 575-579 (2017).

13. Fu, N., Sauer, G. S. \& Lin, S. A general, electrocatalytic approach to the synthesis of vicinal diamines. Nat. Protoc. 13, 1725-1743 (2018).

14. Siu, J. C., Parry, J. B. \& Lin, S. Aminoxyl-catalyzed electrochemical diazidation of alkenes mediated by a metastable charge-transfer complex. J. Am. Chem. Soc. 141, 2825-2831 (2019).

15. Zhao, B., Yuan, W., Du, H. \& Shi, Y. Cu(I)-catalyzed intermolecular diamination of activated terminal olefins. Org. Lett. 9, 4943-4945 (2007).

16. Wen, Y., Zhao, B. \& Shi, Y. Cu(I)-catalyzed diamination of disubstituted terminal olefins: an approach to potent NK1 antagonist. Org. Lett. 11, 2365-2368 (2009)

17. Abrams, R., Lefebvre, Q. \& Clayden, J. Transition metal free cycloamination of prenyl carbamates and ureas promoted by aryldiazonium salts. Angew. Chem. Int. Ed. 57, 13587-13591 (2018).

18. Davies, J., Sheikh, N. S. \& Leonori, D. Photoredox imino functionalizations of olefins. Angew. Chem. Int. Ed. 56, 13361-13365 (2017).

19. Caron, S., Dugger, R. W., Ruggeri, S. G., Ragan, J. A. \& Ripin, D. H. Largescale oxidations in the pharmaceutical industry. Chem. Rev. 106, 2943-2989 (2006). 
20. Zhu, H.-T., Arosio, L., Villa, R., Nebuloni, M. \& Xu, H. Process safety assessment of the iron-catalyzed direct olefin diazidation for the expedient synthesis of vicinal primary diamines. Org. Process Res. Dev. 21, 2068-2072 (2017).

21. Horn, E. J., Rosen, B. R. \& Baran, P. S. Synthetic organic electrochemistry: an enabling and innately sustainable method. ACS Cent. Sci. 2, 302-308 (2016).

22. Yan, M., Kawamata, Y. \& Baran, P. S. Synthetic organic electrochemical methods since 2000: on the verge of a renaissance. Chem. Rev. 117, 13230-13319 (2017)

23. Jiang, Y., Xu, K. \& Zeng, C. Use of electrochemistry in the synthesis of heterocyclic structures. Chem. Rev. 118, 4485-4540 (2018).

24. Mohle, S. et al. Modern electrochemical aspects for the synthesis of valueadded organic products. Angew. Chem. Int. Ed. 57, 6018-6041 (2018).

25. Anton, W. et al. Electrifying organic synthesis. Angew. Chem. Int. Ed. 57, 5594-5619 (2018).

26. Tang, S., Liu, Y. \& Lei, A. Electrochemical oxidative cross-coupling with hydrogen evolution: a green and sustainable way for bond formation. Chem 4, 27-45 (2018).

27. Yoshida, J.-i, Shimizu, A. \& Hayashi, R. Electrogenerated cationic reactive intermediates: the pool method and further advances. Chem. Rev. 118, 4702-4730 (2018).

28. Moeller, K. D. Using physical organic chemistry to shape the course of electrochemical reactions. Chem. Rev. 118, 4817-4833 (2018).

29. Sauermann, N., Meyer, T. H., Qiu, Y., Ackermann, L. Electrocatalytic C-H Activation. activation. ACS Catal. 8, 7086-7103 (2018).

30. Ma, C., Fang, P. \& Mei, T.-S. Recent advances in $\mathrm{C}-\mathrm{H}$ functionalization using electrochemical transition metal catalysis. ACS Catal. 8, 7179-7189 (2018).

31. Kärkäs, M. D. Electrochemical strategies for $\mathrm{C}-\mathrm{H}$ functionalization and $\mathrm{C}-\mathrm{N}$ bond formation. Chem. Soc. Rev. 47, 5786-5865 (2018).

32. Nutting, J. E., Rafiee, M. \& Stahl, S. S. Tetramethylpiperidine N-oxyl (TEMPO), phthalimide N-oxyl (PINO), and related N-oxyl species: electrochemical properties and their use in electrocatalytic reactions. Chem. Rev. 118, 4834-4885 (2018).

33. Francke, R. \& Little, R. D. Redox catalysis in organic electrosynthesis: basic principles and recent developments. Chem. Soc. Rev. 43, 2492-2521 (2014).

34. Ye, Z. \& Zhang, F. Recent advances in constructing nitrogen-containing heterocycles via electrochemical dehydrogenation. Chin. J. Chem. 37, 513-528 (2019).

35. Morofuji, T., Shimizu, A. \& Yoshida, J. Direct C-N coupling of imidazoles with aromatic and benzylic compounds via Electrooxidative $\mathrm{C}-\mathrm{H}$ functionalization. J. Am. Chem. Soc. 136, 4496-4499 (2014).

36. Shäfer, H. Oxidative addition of the azide ion to olefine, a simple route to diamines. Angew. Chem. Int. Ed. 9, 158-159 (1970)

37. Xiong, P. et al. Electrochemically enabled carbohydroxylation of alkenes with $\mathrm{H}_{2} \mathrm{O}$ and organotrifluoroborates. J. Am. Chem. Soc. 140, 16387-16391 (2018).

38. Cai, C.-Y. \& Xu, H.-C. Dehydrogenative reagent-free annulation of alkenes with diols for the synthesis of saturated O-heterocycles. Nat. Commun. 9, 3551 (2018).

39. Monos, T. M., McAtee, R. C. \& Stephenson, C. R. J. Arylsulfonylacetamides as bifunctional reagents for alkene aminoarylation. Science 361, 1369 (2018).

40. Margrey, K. A. \& Nicewicz, D. A. A general approach to catalytic alkene antimarkovnikov hydrofunctionalization reactions via acridinium photoredox catalysis. Acc. Chem. Res. 49, 1997-2006 (2016).

41. Feng, R., Smith, J. A. \& Moeller, K. D. Anodic cyclization reactions and the mechanistic strategies that enable optimization. Acc. Chem. Res. 50, 2346-2352 (2017).

42. Li, J. et al. Electrochemical aziridination by alkene activation using a sulfamate as the nitrogen source. Angew. Chem. Int. Ed. 57, 5695-5698 (2018).

43. Yi, H. et al. Photocatalytic Dehydrogenative cross-coupling of alkenes with alcohols or azoles without external oxidant. Angew. Chem. Int. Ed. 56, 1120-1124 (2017).
44. Johnston, L. J. \& Schepp, N. P. Reactivities of radical cations: characterization of styrene radical cations and measurements of their reactivity toward nucleophiles. J. Am. Chem. Soc. 115, 6564-6571 (1993).

45. Burgbacher, G., Schaefer, H. J. \& Roe, D. C. Kinetics of the anodic dimerization of 4,4'-dimethoxystilbene by the rotating ring-disk electrode. $J$. Am. Chem. Soc. 101, 7590-7593 (1979).

46. Imada, Y., Okada, Y., Noguchi, K. \& Chiba, K. Selective functionalization of styrenes with oxygen using different electrode materials: olefin cleavage and synthesis of tetrahydrofuran derivatives. Angew. Chem. Int. Ed. 58, 125-129 (2019).

47. Steckhan, E. Indirect electroorganic syntheses - a modern chapter of organic electrochemistry. Angew. Chem. Int. Ed. 25, 683-701 (1986).

48. Heaney, H. Boron trifluoride-acetic acid. Encyclopedia of Reagents for Organic Synthesis (2001), https://doi.org/10.1002/047084289X.rb246.

49. Wilger, D. J., Grandjean, J.-M. M., Lammert, T. R. \& Nicewicz, D. A. The direct anti-Markovnikov addition of mineral acids to styrenes. Nat. Chem. 6, 720 (2014).

\section{Acknowledgements}

We acknowledge the financial support of this research from MOST (2016YFA0204100), NSFC (No. 21672178), Program for Changjiang Scholars and Innovative Research Team in University and Fundamental Research Funds for the Central Universities.

\section{Author contributions}

C.Y.C. and X.M.S. performed the experiments and analyzed the data. H.C.X. designed and directed the project and wrote the manuscript.

\section{Competing interests}

The authors declare no competing interests.

\section{Additional information}

Supplementary information is available for this paper at https://doi.org/10.1038/s41467019-13024-5.

Correspondence and requests for materials should be addressed to H.-C.X.

Peer review information Nature Communications thanks the anonymous reviewer(s) for their contribution to the peer review of this work. Peer reviewer reports are available.

Reprints and permission information is available at http://www.nature.com/reprints

Publisher's note Springer Nature remains neutral with regard to jurisdictional claims in published maps and institutional affiliations.

Open Access This article is licensed under a Creative Commons Attribution 4.0 International License, which permits use, sharing, adaptation, distribution and reproduction in any medium or format, as long as you give appropriate credit to the original author(s) and the source, provide a link to the Creative Commons license, and indicate if changes were made. The images or other third party material in this article are included in the article's Creative Commons license, unless indicated otherwise in a credit line to the material. If material is not included in the article's Creative Commons license and your intended use is not permitted by statutory regulation or exceeds the permitted use, you will need to obtain permission directly from the copyright holder. To view a copy of this license, visit http://creativecommons.org/ licenses/by/4.0/

(c) The Author(s) 2019 